\title{
PENGARUH PEMBERIAN PUPUK HAYATI BIOBOOST TERHADAP PERTUMBUHAN DAN HASIL BEBERAPA VARIETAS KACANG TANAH (Arachis hypogaea L.)
}

\author{
Effects of Bioboost liquid biofertilizer on growth and yield varieties of peanut (Arachis \\ hypogaea L.)
}

\author{
Nisrina Arifah ${ }^{1}$, Erita Hayati ${ }^{1}$ dan Nanda Mayani ${ }^{{ }^{*}}$ \\ ${ }^{1}$ Program Studi Agroteknologi, Fakultas Pertanian, Universitas Syiah Kuala
}

\begin{abstract}
Abstrak. Penelitian pengaruh pemberian pupuk hayati Bioboost terhadap pertumbuhan dan hasil beberapa varietas kacang tanah dilaksanakan di Kebun Percobaan Fakultas Pertanian dan Laboratorium Hortikultura Universitas Syiah Kuala, Banda Aceh yang dimulai pada bulan Agustus sampai dengan Desember 2017. Penelitian ini bertujuan untuk mengetahui pengaruh pemberian pupuk hayati dan varietas kacang tanah serta interaksi antara pupuk hayati dan varietas terhadap pertumbuhan dan hasil kacang tanah.Penelitian ini dilakukan dengan menggunakan Rancangan Acak Kelompok (RAK) pola faktorial dengan 2 faktor dan 3 ulangan. Faktor pertama yaitu konsentrasi pupuk hayati Bioboost yang terdiri dari 4 taraf dan faktor kedua yaitu varietas kacang tanah yang terdiri dari 3 taraf. Hasil penelitian menunjukkan bahwa konsentrasi pupuk hayati Bioboost berpengaruh terhadap jumlah polong bernas, berat biji pertanaman dan potensi hasil dengan konsentrasi terbaik yaitu $20 \mathrm{ml} / \mathrm{l}$. Sedangkan untuk varietas berpengaruh terhadap pertumbuhan dan hasil dengan varietas terbaik ialah varietas Tuban
\end{abstract}

Kata kunci: Pupuk Hayati Bioboost, Varietas, Kacang Tanah

\begin{abstract}
The research of Effects Bioboost liquid biofertilizer on growth and yield varieties of peanut has been carried out in experimental garden and laboratorium of horticilture Departement of Agroteknology, Agriculture Faculty, Syiah Kuala University in Banda Aceh was started from August until December 2017. The purpose of this study was to find out about the effect of Bioboost liquid biofertilizer and varieties of peanut and interact between Bioboost liquid biofertilizer with varieties of peanut on growth and yield. The research used group randomized design method consisting of 2 factors and repeated 3 times. The first factos is consentration of Bioboost liquid fertilizer consisting of 4 levels and the second factor is varieties of peanut consisting 3 levels. Results of the research showed consentration of Bioboost liquid biofertilizer was effected on number of pods, plant seed weight and harvest with the best consentration was $20 \mathrm{ml} / \mathrm{l}$. While for varietiy was effected growth and yield with the best variety was Tuban
\end{abstract}

Keywords : Bioboost Liquid Biofertilizer, Variety, Peanut

\section{PENDAHULUAN}

Kacang tanah (Arachis hypogaea L.) merupakan salah satu jenis tanaman yang banyak dikonsumsi masyarakat Indonesia . Kebutuhan kacang tanah terus meningkat setiap tahunnya. Permasalahan yang dihadapi ialah produktivitas tanaman kacang tanah yang masih rendah dan berkurangnya lahan yang produktif (Rambitan dan Sari, 2013).

Produksi kacang tanah di Indonesia pada tahun 2014 mencapai 638.896 ton namun pada tahun 2015 produksi kacang tanah menurun mencapai 605.127 ton(BPS, 2015). Begitu pula dengan produksi kacang tanah di provinsi Aceh yang menurun sampai 553 ton dari tahun 2014 hingga 2015. Perbedaan jumlah produktivitas kacang tanah bukan hanya karena perbedaan teknologi, tetapi adanya pengaruh faktor-faktor lain yaitu sifat atau karakter agroklimat, serangan hama dan penyakit, varietas yang ditanam, umur panen serta usaha tani lainnya (Suwardjono, 2004)

Upaya untuk meningkatkan produksi kacang tanah antara lain dengan pemupukan dan penggunaan varietas unggul. Menurut Marpaung (2014), penggunaan pupuk buatan (anorganik) secara terus menerus dapat menipiskan ketersedian unsur-unsur mikro yang ada didalam tanah. Oleh karena itu, untuk mengurangi dampak dari pemakaian pupuk anorganik secara berlebihan yaitu dengan menggunakan bahan-bahan organik. Varietas unggul yang 
ditanam di tanah yang subur dapat memberikan hasil yang cukup baik khususnya kacang tanah agar dapat memenuhi kebutuhan Nasional yang masih jauh lebih besar dibandingkan dengan produksinya.

Salah satu upaya untuk meningkatkan produksi kacang tanah yaitu dengan cara pemupukan seperti menggunakan pupuk hayati. Pupuk hayati merupakan mikroba yang diberikan ke dalam tanah untuk meningkatkan pengambilan hara oleh tanaman dari dalam tanah maupun udara. Pupuk ini mengandung mikroorganisme tanah yang unggul dan bermanfaat untuk meningkatkan kesuburan tanah sebagai hasil proses biokimia tanah.

Keunggulan dari pupuk Bioboost ini adalah bentuknya cair sehingga mudah dan cepat diserap oleh tanaman, mengandung bakteri unggul hasil proses isolasi dan pembiakan murni diantaranya Azotobacter sp dan Azospirilium sp sebagai penambat nitrogen, Bacillus sp dan Chytophaga sp sebagai dekomposisi bahan organik, serta Pseudomonas sp sebagai dekomposisi residu kimia (Manuhutu et al., 2014). Menurut Pal et al. (2000) mikroba Pseudomonas dapat meningkatkan serapan hara $\mathrm{N}$ dan $\mathrm{P}$ pada tanaman kacang tanah.

Manfaat dari penggunaan pupuk Bioboost adalah menghemat penggunaan pupuk kimia 50\%-60\%, meningkatkan jumlah pengikatan Nitrogen bebas oleh bakteri, meningkatkan proses biokimia di dalam tanah, memperbaiki strukur tanah sehingga menjadi lebih subur. Selain itu, pupuk hayati Bioboost juga dapat mempercepat pertumbuhan hingga panen, hasil panen dapat memenuhi standar organik, meningkatkan kesehatan tanaman dan hasil pertanian lebih sehat dan ramah lingkungan. ${ }^{1)}$

Pemberian pupuk hayati Bioboost pada konsentrasi yang tinggi dapat meningkatkan berat segar tanaman, berat segar akar, berat kering tanaman, berat kering akar, dan volume akar pada tanaman selada yang artinya, tanaman (tajuk dan akar) didominasi oleh fotosintat yang terbentuk dengan baik akibat pemberian pupuk. Pemberian konsorsium bakteri (Bioboost) dengan konsentrasi $40 \mathrm{ml} /$ liter air pada tanaman padi memiliki pertumbuhan dan hasil terbaik (Yanti, 2015). Menurut Rusmawarni et al. (2016), pemberian Bioboost dengan dosis $10 \mathrm{ml} /$ polybag pada tanaman stroberi memberikan pertumbuhan yang lebih baik dibandingkan dengan perlakuan lainnya.

Selain pemupukan faktor lain yang mempengaruhi peningkatkan produksi yaitu penggunaan varietas unggul. Setiap varietas memiliki respon yang berbeda-beda terhadap faktor eskternal seperti input yang diberikan dan setiap varietas yang cocok pada lingkungan tertentu belum tentu cocok pada lingkungan lainnya (Efendi, 2010, dalam Dwipa, 2017).

Balitkabi Malang telah menghasilkan beberapa varietas yang tahan terhadap penyakit seperti varietas Domba dan kelinci, yang agak tahan penyakit karat dan bercak daun serta varietas Tuban yang tahan layu, toleran karat dan bercak daun serta toleran kekeringan dan varietas Bima yang agak tahan penyakit layu bakteri (Balitkabi, 2016). Menurut Fattah (2011), varietas Domba memiliki jumlah polong per tanaman lebih tinggi jika dibandingkan dengan varietas Jerapah dan Bison, karena varietas Domba memiliki kemampuan untuk membentuk cabang dan bintil-bintil akar yang banyak sehingga mampu menghasilkan polong yang lebih banyak.. Varietas Kelinci memiliki polong hampa yang sedikit sehingga polong bernas lebih banyak. Hal ini menunjukkan bahwa varietas Kelinci memiliki keunggulan dalam produksinya ( Hayati et al., 2012).

Varietas Domba memiliki kriteria lebih cepat saat muncul ginofor dibandingkan dengan varietas Jerapah, Bima, Tuban, Kelinci dan Bison (Sufianto, 2011). Varietas Tuban memiliki karakteristik polong ideal baik dilihat dari sisi ukuran polong, maupun ukuran biji serta retikulasi kulit polong sehingga sangat diminati perusahaan kacang (Purnomo, 2005)

Berdasarkan permasalahan di atas, maka penelitian ini dilaksanakan untuk mengetahui tentang pertumbuhan dan hasil akibat pemberian pupuk hayati Bioboost dengan beberapa varietas kacang tanah. 


\section{METODE PENELITIAN}

\section{Tempat dan Waktu Penelitian}

Penelitian ini dilaksanakan di kebun percobaan dan laboratorium Hortikultura Fakultas Pertanian Universitas Syiah Kuala Darussalam Banda Aceh dengan letak geografis 5 34 '00'N 95022’32”E mulai Agustus sampai Desember 2017.

\section{Alat dan Bahan Penelitian}

Alat yang digunakan dalam penelitian ini antara lain: cangkul, garu, gembor, meteran, timbangan analitik, gelas ukur, hand traktor, alat tulis, dan papan nama. Bahan yang akan digunakan dalam penelitian ini ialah benih kacang tanah varietas Domba (600 benih), varietas Kelinci (600 benih) dan varietas Tuban (600 benih) yang berasal dari Balitkabi malang, pupuk hayati Bioboost $(8100 \mathrm{ml})$, pupuk kandang (20 ton/ha dibutuhkan sebanyak $162 \mathrm{~kg}$ ), Urea (45kg/ha dibutuhkan sebanyak $365 \mathrm{~g})$, SP-36 (50kg/ha dibutuhkan sebanyak $405 \mathrm{~g})$, dan $\mathrm{KCl}$ $(25 \mathrm{~kg} / \mathrm{ha}$ dibutuhkan sebanyak $203 \mathrm{~g}$ ).

\section{Rancangan Penelitian}

Penelitian ini dilakukan dengan menggunakan Rancangan Acak Kelompok (RAK) pola Faktorial dengan 2 faktor dan 3 ulangan. Faktor pertama yaitu konsentrasi pupuk hayati (P) yang terdiri dari 4 taraf yaitu: $B_{1}=0 \mathrm{ml} / 1$ air; $B_{1=} 20 \mathrm{ml} / 1$ air; $B_{2}=40 \mathrm{ml} / 1$ air; $B_{3}=60 \mathrm{ml} / 1$ air. Faktor kedua adalah varietas kacang tanah $(\mathrm{V})$ yang terdiri dari 3 taraf yaitu: $\mathrm{V}_{1}=$ Domba; $\mathrm{V}_{2}=$ Kelinci; $\mathrm{V}_{3}=$ Tuban. sehingga diperoleh 12 kombinasi perlakuan dan 36 unit percobaan. Susunan perlakuan dapat dilihat pada Tabel 1.

Tabel 1. Susunan Kombinasi Perlakukan Antara Konsentrasi Pupuk Hayati Bioboost (P) dan Varietas Kacang Tanah (V)

\begin{tabular}{ccc}
\hline Kombinasi Perlakuan & $\begin{array}{c}\text { Konsentrasi Pupuk Hayati } \\
(\mathbf{m l} / \mathbf{l} \text { air })\end{array}$ & Varietas \\
\hline $\mathrm{P}_{0} \mathrm{~V}_{1}$ & 0 & Domba \\
$\mathrm{P}_{0} \mathrm{~V}_{2}$ & 0 & Kelinci \\
$\mathrm{P}_{0} \mathrm{~V}_{3}$ & 0 & Tuban \\
$\mathrm{P}_{1} \mathrm{~V}_{1}$ & 20 & Domba \\
$\mathrm{P}_{1} \mathrm{~V}_{2}$ & 20 & Kelinci \\
$\mathrm{P}_{1} \mathrm{~V}_{3}$ & 20 & Tuban \\
$\mathrm{P}_{2} \mathrm{~V}_{1}$ & 40 & Domba \\
$\mathrm{P}_{2} \mathrm{~V}_{2}$ & 40 & Kelinci \\
$\mathrm{P}_{2} \mathrm{~V}_{3}$ & 40 & Tuban \\
$\mathrm{P}_{3} \mathrm{~V}_{1}$ & 60 & Domba \\
$\mathrm{P}_{3} \mathrm{~V}_{2}$ & 60 & Kelinci \\
$\mathrm{P}_{3} \mathrm{~V}_{3}$ & 60 & Tuban \\
\hline
\end{tabular}

Keterangan: $\mathrm{P}=$ Konsentrasi Pupuk Hayati Bioboost; V= Varietas Kacang Tanah

\section{Prosedur Penelitian}




\section{Pengolahan Tanah}

Pengolahan tanah dilakukan dua minggu sebelum tanam. Tanah diolah dengan hand traktor dan dicangkul terlebih dahulu kemudian diratakan dengan menggunakan garu sekaligus membersihkan gulma dan menghaluskan bongkahan-bongkahan tanah.

\section{Pembuatan Bedengan}

Bedengan dibentuk dengan ukuran $1,5 \mathrm{~m} \times 1,5 \mathrm{~m}$ dan tinggi bedengan $20 \mathrm{~cm}$ sebanyak 36 bedengan, jarak antar ulangan $50 \mathrm{~cm}$ dan jarak antar bedengan $40 \mathrm{~cm}$, selanjutnya dipasang papan nama pada setiap bedengan.

\section{Pembuatan Lubang Tanam}

Penanaman dilakukan dengan jarak tanam $25 \mathrm{~cm} \times 25 \mathrm{~cm}$ dengan cara melubangi tanah dengan kedalaman $\pm 2 \mathrm{~cm}$, kemudian dimasukkan 2 benih perlubang tanam dan ditutup dengan tanah.

\section{Pemupukan Dasar}

Pupuk dasar yang digunakan ialah pupuk kandang, pupuk urea, SP-36 dan KCl. Selain itu pupuk hayati yang digunakan ialah pupuk hayati Bioboost. Pupuk kandang diberikan seminggu sebelum tanam dengan cara disebarkan di bedengan. Total kebutuhan pupuk kandang 20 ton/ha $(4,5 \mathrm{~kg} / \mathrm{bedeng})$. Pemberian pupuk urea dilakukan dua kali pemberian pertama pada saat penanaman dengan dosis $15 \mathrm{~kg} / \mathrm{ha}(3,38 \mathrm{~g} / \mathrm{bedeng})$ dan pada umur $30 \mathrm{HST}$ dengan dosis $30 \mathrm{~kg} / \mathrm{ha}$ yaitu urea $(6,75 \mathrm{~g} /$ bedeng). Pemberian SP-36 dan $\mathrm{KCl}$ satu kali pemberian pada saat penanaman SP-36 dengan dosis $50 \mathrm{~kg} / \mathrm{ha}(11,25 \mathrm{~g} / \mathrm{bedeng})$ dan untuk $\mathrm{KCl}$ dengan dosis $25 \mathrm{~kg} / \mathrm{ha}$ (11,25 g/bedeng). Pupuk urea, SP-36 dan $\mathrm{KCl}$ sudah dikurangi dosisnya $50 \%$ dari dosis anjuran dan pupuk diberikan dengan cara larikan.

\section{Pengaplikasian Pupuk Hayati Bioboost}

Pupuk hayati Bioboost diberikan tiga kali pada satu kali penanaman yaitu tiga hari sebelum tanam, 30 HST (Hari Setelah Tanam) dan 60 HST. Konsentrasi pupuk Bioboost yang digunakan sesuai perlakuan ialah $\mathrm{P}_{0}=0 \mathrm{ml} /$ liter air, $\mathrm{P}_{1}=20 \mathrm{ml} / \mathrm{liter}$ air, $\mathrm{P}_{2}=40 \mathrm{ml} / \mathrm{liter}$ air, dan $\mathrm{P}_{3}=60 \mathrm{ml} /$ liter air. Pupuk cair ini diberikan dengan cara menyiramnya ke tanah di sekitar akar tanaman sebanyak $100 \mathrm{ml}$ per tanaman

\section{Penanaman}

Penanaman dilakukan dengan memasukkan 2 benih per lubang tanam dan ditutupi dengan tanah. Pada umur 1 minggu setelah tanam disisakan 1 tanaman.

\section{Pemeliharaan}

a. Penyiangan dan Pembumbunan

Penyiangan dan pembumbunan dilakukan 14, 28 dan 42 HST. Penyiangan gulma dilakukan secara manual yaitu dengan cara mencabut gulma yang ada di sekitar tanaman. Pembumbunan bertujuan agar semua ginofor tertutup oleh tanah dan memperkuat tumbuhnya tanaman serta memelihara struktur tanah agar tetap gembur.

b. Penyiraman

Penyiraman dilakukan dua kali sehari dengan gembor yaitu pagi dan sore hari atau tergantung kondisi cuaca di lapangan.

\section{Pengendalian Hama dan Penyakit}

Hama dan penyakit yang menyerang belum merugikan tanaman sehingga belum perlu dilakukan pengendalian 


\section{Pemanenan}

Pemanenan kacang tanah dilakukan dengan kriteria $75 \%$ daun sudah menguning dan polong sudah berwarna coklat, keras dan bila dibuka biji telah terisi penuh. Varietas Domba umur panen 90-95 hari, varietas Kelinci umur panen 95 hari dan varietas Tuban 90-95 hari.

\section{Peubah yang diamati}

\section{Tinggi Tanaman $(\mathbf{c m})$}

Pengamatan dilakukan pada 5 tanaman sampel per bedeng saat tanaman berumur 14, 21 dan 28 HST. Tinggi tanaman diukur dari permukaan tanah yang telah diberi tanda sampai titik tumbuh dengan menggunakan meteran.

\section{Berat Biji per Tanaman (gram)}

Kacang tanah yang telah dipisah dengan kulit polongnya pada tanaman sampel ditimbang dengan menggunakan timbangan analitik.

\section{Potensi Hasil (ton/ha)}

Pengamatan potensi hasil per hektar diamati dengan cara dikonversi dari berat biji per tanaman

Potensi hasil $=\frac{\text { luas lahan } 1 \text { ha }}{\text { jarak tanam }} \times$ hasil $/$ tanaman

\section{HASIL DAN PEMBAHASAN}

\section{Pengaruh Konsentrasi Pupuk Hayati Bioboost Terhadap Pertumbuhan dan Hasil Kacang Tanah}

Hasil uji $\mathrm{F}$ analisis ragam menunjukkan bahwa pupuk hayati Bioboost berpengaruh nyata terhadap berat biji per tanaman dan potensi hasil. Rata-rata pertumbuhan dan hasil tanaman kacang tanah akibat pemberian pupuk hayati Bioboost dapat dilihat pada Tabel 2.

Tabel 2. Rata-rata pertumbuhan dan hasil tanaman kacang tanah akibat pemberian pupuk hayati Bioboost

\begin{tabular}{|c|c|c|c|c|c|c|}
\hline \multirow{2}{*}{\multicolumn{2}{|c|}{ Parameter yang diamati }} & \multicolumn{4}{|c|}{ Konsentrasi pupuk hayati Bioboost (ml/l) } & \multirow{2}{*}{$\begin{array}{l}\text { BNT } \\
0,05\end{array}$} \\
\hline & & $0\left(\mathrm{P}_{0}\right)$ & $20\left(\mathrm{P}_{1}\right)$ & $40\left(\mathrm{P}_{2}\right)$ & $60\left(\mathrm{P}_{3}\right)$ & \\
\hline \multirow{3}{*}{ Tinggi tanaman $(\mathrm{cm})$} & 14 HST & 3,86 & 3,98 & 3,99 & 4,35 & - \\
\hline & $21 \mathrm{HST}$ & 4,77 & 5,26 & 5,35 & 5,70 & - \\
\hline & $28 \mathrm{HST}$ & 8,36 & 9,03 & 8,01 & 8,86 & - \\
\hline \multicolumn{2}{|c|}{ Berat biji pertanaman $(\mathrm{g})$} & $13,45 \mathrm{a}$ & $17,86 \mathrm{bc}$ & $19,07 \mathrm{c}$ & $15,04 \mathrm{ab}$ & 4,06 \\
\hline \multicolumn{2}{|l|}{ Potensi hasil (ton/ha) } & $1,80 \mathrm{a}$ & $2,36 \mathrm{bc}$ & $2,54 \mathrm{c}$ & $1,95 \mathrm{ab}$ & 0,54 \\
\hline
\end{tabular}

Keterangan : Angka yang diikuti oleh huruf yang sama pada baris yang sama berbeda tidak nyata pada taraf $5 \%\left(\mathrm{Uji}_{\mathrm{BNT}} \mathrm{B}_{05}\right)$

Hasil penelitian menunjukkan konsentrasi pupuk hayati Bioboost berpengaruh tidak nyata terhadap tinggi tanaman. Namun pada konsentrasi $20 \mathrm{ml} / \mathrm{l}$ cenderung lebih baik dibandingkan dengan konsentrasi lainnya. Menurut Sinulingga et al. (2015) keberhasilan penggunaan pupuk hayati tidak hanya dipengaruhi oleh kuantitas mikroba namun salah satunya faktor lingkungan seperti suhu dan curah hujan. Selain itu bahan organik yang rendah juga dapat menunjukkan pengaruh yang tidak nyata. Mikroba mampu hidup bersama tanaman inangnnya sehingga keuntungan diperoleh oleh keduanya.

Konsentrasi pupuk hayati Bioboost berpengaruh nyata terhadap berat biji pertanaman dan potensi hasil. Beberapa konsentrasi pupuk hayati Bioboost $40 \mathrm{ml} / \mathrm{l}$ memberikan hasil yang 
lebih baik dibandingkan dengan konsentrasi lainnya. Hal ini didukung dengan penelitian Yanti et al. (2015) bahwa konsentrasi $40 \mathrm{ml} / \mathrm{l}$ konsorsium bakteri (Bioboost) pada parameter jumlah gabah berisi per malai, menunjukkan hasil yang lebih baik dibandingkan dengan perlakuan $20 \mathrm{ml} / \mathrm{l}$. Hal ini diduga karena konsentrasi yang optimal maka hormon dan mikroorganisme yang terkandung dalam pupuk hayati Bioboost bekerja secara optimal. Sesuai dengan pernyataan Kalay et al. (2016) azotobacter, azospirilium, acinotobacter, dan pseudomonas yang terkandung dalam pupuk menghasilkan hormon pertumbuhan, sehingga pertumbuhan dan hasil meningkat.

Umumnya mikroba dalam tanah mampu hidup bersama tanaman inangnya sehingga keduanya mendapatkan keuntungan, mikroba mendapatkan bahan organik untuk aktivitasnya dan tanaman inang mendapatkan tambahan unsur hara. Pemberian beberapa mikroba yang bersinergi dalam menyediakan unsur hara seperti Rhizobium sp sebagai penambat Nitrogen, Bacillus sp dan Pseudomonas sp sebagai pelarut posfat dan penghasil fitohormon berperan dalam pertumbuhan kacang tanah (Siregar et al., 2017). Pupuk hayati Bioboost selain mengandung mikroorganisme juga mengandung hormon yang dapat memacu pertumbuhan tanaman dan mikroorganisme dapat meningkatkan pengambilan hara dari tanah. Sejalan dengan pernyataan Wibowo et al. (2009) peningkatan hormon sitokinin dapat meningkatan jumlah cabang dan daun yang akan memacu peningkatan laju fotosintesis sehingga produksi kacang tanah akan semakin tinggi.

\section{Pengaruh Beberapa Varietas Kacang Tanah Terhadap Pertumbuhan dan Hasil Kacang Tanah}

Hasil uji $\mathrm{F}$ analisis ragam menunjukkan bahwa beberapa varietas kacang tanah berpengaruh sangat nyata terhadap jumlah tinggi tanaman 28 HST dan pengaruh yang nyata terdapat pada tinggi 14 HST dan 21 HST. Rata-rata pertumbuhan dan hasil tanaman akibat perlakuan beberapa varietas kacang tanah dapat dilihat pada Tabel 3.

Tabel 3. Rata-rata pertumbuhan dan hasil tanaman akibat perlakuan beberapa varietas kacang tanah

\begin{tabular}{|c|c|c|c|c|c|}
\hline \multirow{2}{*}{\multicolumn{2}{|c|}{ Parameter yang diamati }} & \multicolumn{3}{|c|}{ Varietas kacang tanah } & \multirow{2}{*}{$\begin{array}{l}\text { BNT } \\
0,05\end{array}$} \\
\hline & & Domba $\left(\mathrm{V}_{1}\right)$ & Kelinci $\left(\mathrm{V}_{2}\right)$ & Tuban $\left(\mathrm{V}_{3}\right)$ & \\
\hline \multirow{3}{*}{ Tinggi tanaman $(\mathrm{cm})$} & $14 \mathrm{HST}$ & $3.84 \mathrm{a}$ & $3,90 \mathrm{a}$ & $4,40 \mathrm{~b}$ & 0,38 \\
\hline & $21 \mathrm{HST}$ & $4,71 \mathrm{a}$ & $5,19 \mathrm{ab}$ & $5,90 \mathrm{~b}$ & 0,74 \\
\hline & 28 HST & 7,08 a & $7,53 \mathrm{~b}$ & $11,08 \mathrm{c}$ & 0,04 \\
\hline \multicolumn{2}{|c|}{ Berat biji pertanaman $(\mathrm{g})$} & 16,22 & 17,47 & 15,38 & - \\
\hline \multicolumn{2}{|l|}{ Potensi hasil (ton/ha) } & 2,16 & 2,28 & 2,04 & - \\
\hline
\end{tabular}

Keterangan : Angka yang diikuti oleh huruf yang sama pada baris yang sama berbeda tidak nyata pada taraf $5 \%\left(\mathrm{Uji}_{\mathrm{BNT}} \mathrm{B}_{05}\right)$

Hasil penelitian menunjukkan bahwa pertumbuhan kacang tanah terbaik di jumpai pada varietas Tuban. Hal ini diduga varietas Tuban memiliki genotip yang menunjukkan respon tinggi tanaman lebih tinggi dibandingkan dengan varietas Domba dan Kelinci sehingga jumlah cabang dan jumlah ginofor juga lebih banyak. Hal ini sesuai dengan pernyataan Rahman et al. (2015) tinggi tanaman kacang tanah pada 28 dan 56 HST lebih tinggi dijumpai pada varietas Tuban dibandingkan dengan varietas Talam, varietas Kancil dan varietas Lokal. Menurut Yusuf (2014) setiap varietas tanaman pada kondisi lingkungan hidupnya mendapatkan respon yang berbeda pada pertumbuhannya.

Pada berat biji pertanman dan potensi hasil berpengaruh tidak nyata. Menurut Sufianto (2011) kebutuhan dan daya simpan tiap-tiap varietas berbeda sesuai dengan kebutuhan energi untuk berkecambah. Ukuran polong dan biji setiap varietas berbeda karena memiliki 
karakteristik genotip yang berbeda. Damanik et al. (2017) menyatakan bahwa ukuran biji dipengaruhi oleh genetik tanaman tersebut. Menurut Jedeng (2011), mengatakan bahwa secara umum tinggi rendahnya produksi suatu tanaman tergantung dari faktor varietas, bagaimana cara bercocok tanam dan kondisi lingkungan tempat di mana tanaman itu ditanam.

\section{KESIMPULAN}

Konsentrasi pupuk hayati Bioboost berpengaruh nyata terhadap berat biji pertanaman dan potensi hasil. Konsentrasi pupuk hayati Bioboost terbaik dijumpai pada $20 \mathrm{ml} / \mathrm{l}$ air. Varietas berpengaruh sangat nyata terhadap jumlah tinggi tanaman 28 HST dan pengaruh yang nyata terdapat pada tinggi 14, 21 HST dan berat polong per tanaman. Varietas terbaik dijumpai pada varietas Tuban.

\section{DAFTAR PUSTAKA}

Balai penelitian kacang-kacangan dan umbi-umbian. 2016. Deskripsi varietas unggul kacang tanah. Balai Penelitian Tanaman Kacang-Kacangan dan Umbi-Umbian. Malang.

BPS. 2015. Berita Resmi Statistik, Badan Statistik Provinsi Aceh.

Damanik, D, S, Murniati dan Isnaini. 2017. Pengaruh pemberian solid kelapa sawit dan NPK terhadap pertumbuhan dan produksi kacang tanah (Arachis hypogaea L.). Jurnal faperta. 4 (2):1-13.

Efendi. 2010. Peningkatan pertumbuhan dan produksi kedelai melalui kombinasi pupuk organik lamtorogung dengan pupuk kandang. Dalam Dwipa, I., Saswita W. pengujian hasil dan mutu benih beberapa varietas kedelai dengan variasi jumlah satuan panas panen. Pros Seminar Nasional Masyarakat Biodiv Indonesia 2: 16-22.

Fattah, A. 2011. Kajian penggunaan varietas unggul baru kacang tanah di lahan sawah tadah hujan. Jurnal Agrivigor. 10 (3): 284-29.

Hayati, M, A. Marliah dan H. Fajri. 2010. Pengaruh varietas dan dosis pupuk SP-36 terhadap pertumbuhan dan hasil tanaman kacang tanah (Arachis hypogaea L.). Jurnal Agrista. 16 (1): 7-13.

Jedeng, I. W. 2011. Pengaruh jenis dan dosis pupuk organik terhadap pertumbuhan dan hasil ubi jalar (Ipomea batatas (.L) Lamb) varietas lokal ungu. Tesis. Program Pasca Sarjana Universitas Udayana, Denpasar.

Kalay, A. M., R. Hindersah, A. Talahaturuson dan A. F. Langoi. 2016. Efek pemberian pupuk hayati konsorsium terhadap pertumbuhan dan hasil tanaman sawi (Brassica juncea L.). Jurnal Agroekotek. 8 (2): 131 - 138.

Manuhutu. A. P., H. Rehatta dan J. J. G. Kailola. 2014. Pengaruh konsentrasi pupuk hayati Bioboost terhadap peningkatan produksi tanaman selada (Lactuta sativa). Jurnal Agrologi. 3 (1): 18-27. 
Marpaung, A. E. 2014. Pemanfaatan pupuk organik padat dan pupuk organik cair dengan pengurangan pupuk anorganik terhadap pertumbuhan tanaman jagung (Zea mays L). Jurnal Saintech. $6: 8-15$ (4).

Purnomo, J. 2005. Meningkatkan produksi kacang tanah lahan alfisol dengan menanam varietas toleran. Diterbitkan di Buletin Palawija No. 10 : 78-84.

Rahman, T., I. C. Siagian dan W. Wibawa. 2015. Influence of addition of ameliorant on productivity of peanut on acidic dry land in Bengkulu Province. International Seminar on Promoting Local Resources for Food and Health. 12-13 October. 2015. 222-227. Bengkulu, Indonesia.

Rambitan. V. M. M dan M. P. Sari. 2013. Pengaruh pupuk kompos cair kulit pisang kepok (Musa Paradisiaca L.) terhadap pertumbuhan dan hasil tanaman kacang tanah (Arachis hypogaea L.) Jurnal Edubio Tropika. 1 (1): 14-24.

Rusmawarni, Djufri dan Suprianto. 2016. Pengaruh berbagai konsentrasi pupuk organik cair dari urin sapi dan pupuk hayati bioboost terhadap pertumbuhan tanaman stoberi (Fragaria virginiana). Jurnal EduBio Tropika. 4 (2) : 16-19

Sinulingga. E. S., J. Ginting dan T. Sabrina. 2015. Pengaruh pemberian pupuk hayati cair dan pupuk NPK terhadap pertumbuhan bibit kelapa sawit di pre nursery. Jurnal Agroekoteknologi. 3 (3): 1219-1225.

Siregar, S. H., L. Mawarni dan T, Irmansyah. 2017. Pertumbuhan dan produksi kacang tanah (Arachis hypogaea L.) dengan beberapa sistem olah tanah dan asosiasi mikroba. Jurnal Agroekoteknologi FP USU. 5(1) :202-207.

Sufianto. 2011. Kriteria bunga menjadi polong bernas pada beberapa varietas kacang tanah (Arachis hypogaea L.). Jurnal Gamma. 6 (2): 137-142

Suwardjono. 2004. Pengaruh beberapa jenis pupuk kandang terhadap pertumbuhan dan produksi kacang tanah. http//www.ut.ac.id/jmst/jurnal/Suwardjono/pengaruh. Html. Diakses pada tanggal 1 Februari 2017.

Wibowo, S. T., Hamim dan A. T. Wahyudi. 2009. Kandungan IAA, serapan hara, pertumbuhan dan produksi jagung dan kacang tanah sebagai respon terhadap aplikasi pupuk hayati. Jurnal Ilmu Pertanian Indonesia 14 (3) :177-183.

Yanti, F., K. Hariyono., I. Sadiman. 2015. Aplikasi konsorsium bakteri terhadap pertumbuhan dan hasil pada beberapa varietas padi . Berkala Ilmiah Pertanian. 1 (1): 1-5.

Yusuf, T. M. 2014. Karakter agronomi beberapa varietas dan dosis pupuk $\mathrm{KCl}$ terhadap pertumbuhan dan hasil kacang tanah (Arachis hypogaea L.). Skripsi. Fakultas Pertanian Universitas Teuku Umar, Meulaboh. 